\title{
WASTEWATER SLUDGE CONVECTIVE DRYING: INFLUENCE OF SLUDGE ORIGIN
}

\author{
A. LÉONARD*, P. VANDEVENNE, T. SALMON, P. MARCHOT, M. CRINE \\ Laboratory of Chemical Engineering, Department of Applied Chemistry, University of Liège, B6c \\ Sart Tilman, 4000 Liège, Belgium. Fax. +3243662818; E-mail: A.Leonard@ulg.ac.be
}

\begin{abstract}
This paper deals with thermal drying of wastewater sludges, whose management will become crucial in the forthcoming years. Sludges collected after mechanical dewatering in 5 different WWTPs are submitted to the same convective drying treatment in order to try finding some relations between the drying behaviours, the type of effluent and wastewater treatments. Results show clearly sludge drying remains a particularly complex operation because sludges may exhibit very different behaviours, both from kinetic and texture points of view. Initial moisture content and global composition are not sufficient to explain the different observed behaviours. It is too early to claim one or another type of water treatment has an influence on the drying behaviour. However, the drying rates can be classified in the inverse order of the organic content. Moreover for sludges at the same siccities, the harder the material (rheological properties), the higher the drying rate. Final textural properties can be related to the rheological properties and the internal diffusion limitations lowering the drying intensity.
\end{abstract}

Keywords: wastewater treatment, sludge management, X-ray microtomography, thermal drying, rheology.

\section{INTRODUCTION}

According the directive of the Council of European Communities concerning urban wastewater treatment [1], municipalities will have to face with growing amounts of wastewater sludges. Their production is expected to double between 1992 and 2005 [2]. At the same time, the directive on waste 
landfill [3] plans the progressive reduction of sludge disposal in dump sites, which is currently the second issue for sludge after landspreading [4-5]. This explains that sludge management will become a real challenge of the years to come.

Two major issues will remain for sludge disposal: incineration and landspreading. In both cases, drying is and will remain a critical and necessary pretreatment after mechanical dewatering by centrifugation or filtration. It can indeed reduce the water content below 5\% dry solids (DS). This obviously reduces the mass and volume of waste and, consequently, the cost for storage, handling and transport. The removal of water to such a low level increases drastically the lower calorific value, transforming the sludge into an acceptable combustible. Furthermore, the dried sludge is a pathogen free, stabilized material because of the high temperature treatment. Despite the industrial and economic importance of such process, rather few works have been carried out in order to get a better understanding of the key - rate controlling - mechanisms. The main practical consequence is that the drying behaviour of a sludge is still difficult to predict. Research in this field is however progressively growing, as indicated by recent publications [6-10].

Activated sludges are heterogeneous mixtures of microorganisms, mineral particles, colloids, organic polymers and cations, whose composition varies considerably depending on sample origin. Their drying behaviour may strongly vary from one sludge sample to another. This study investigates the convective drying of sludges coming from 5 different wastewater treatment plants (WWTP) in order to try finding some relations between the drying behaviours, the type of effluent (domestic or industrial) and wastewater treatments. As mechanical characteristics have an effect on the drying properties [11], rheological properties of each sludge are determined.

\section{MATERIALS AND METHODS}

Sludge Samples 
Sludges have been collected after the mechanical dewatering step in 5 WWTPs whose principal characteristics are listed in Table 1. Table 2 presents dry solids (DS) and volatiles solids (VS) contents of each sludge, determined according Standard Methods [12]. Sludge E, dewatered by centrifugation, exhibits the highest dry solids content, while the digested sludge $\mathrm{C}$ has the lowest one. According to volatile solids contents, sludges are mainly organic, with highest values for sludges coming from plants D and $\mathrm{E}$, equipped with nutrient removal stages. In order to estimate the effect of dry solid contents on drying and rheological behaviour, thickened sludge samples have been collected before dewatering step in WWTP B (see Table 2). These samples have been dewatered in a normalized filtration-expression cell in order to obtain dry solids contents ranging between 12.9 and $15.4 \%$ [13].

Before drying, sludge samples have been extruded through a circular die of $12 \mathrm{~mm}$ and cut at a height of $15 \mathrm{~mm}$, yielding cylindrical samples with volume and mass of approximately $1.7 \mathrm{~cm}^{3}$ and $2 \mathrm{~g}$, respectively, as used in several industrial belt dryers.

\section{Convective Drying Rig}

Convective drying experiments have been carried out in a so-called 'micro-drier' specially designed for handling small extruded samples with a mass between 0.5 and $5 \mathrm{~g}$. The micro-drier is a classical convective rig controlled in relative humidity, temperature and air velocity, which has already been described in detail in a previous paper [10]. Drying curves representing the drying rate $\left(\mathrm{kg} \mathrm{s}^{-1}\right)$ versus the water content on a dry basis $\mathrm{W}\left(\mathrm{kg} \mathrm{kg}^{-1}\right)$ are calculated from these mass versus time data. Dividing the drying rate by the external exchange area yields the so-called Krisher's curves commonly used to study drying, i.e., the mass flux $\left(\mathrm{kg} \mathrm{m}^{-2} \mathrm{~s}^{-1}\right)$ versus water content $\left(\mathrm{kg} \mathrm{kg}^{-1}\right)$. Results reported in this study refer to the following operating conditions: temperature of $160^{\circ} \mathrm{C}$, superficial velocity of $3 \mathrm{~m} \mathrm{~s}^{-1}$, ambient humidity. Ambient humidity fluctuates from one day to another one, ranging between 0.004 and $0.010 \mathrm{~kg} / \mathrm{kg}$. Such variations can however be neglected, at a high temperature, when compared to the external driving force. 
X-ray Microtomograph

$\mathrm{X}$-ray microtomography is used to follow shrinkage and determine the external exchange area of the sample needed to compare drying behaviours. It also allows the detection and quantification of internal cracks or any other modification of the sludge texture. The microtomograph used in this study is a "Skyscan-1074 X-ray scanner" (Skyscan, Belgium). The X-ray source operates at $40 \mathrm{kV}$ and $1 \mathrm{~mA}$. The detector is a $2 \mathrm{D}, 768 \times 576$ pixels, 8 -bit $\mathrm{X}$-ray camera with a spatial resolution of $41 \mu \mathrm{m}$. The sludge sample is periodically (approximately every 5 minutes) removed from the micro-drier and placed in the microtomograph. Once the sample is placed in the microtomograph a zone covering a height of $1 \mathrm{~cm}$ is selected to record a series of 2D scans. The number of angular positions is restricted in order to limit acquisition time at about 2 minutes. This allows avoiding relaxation of internal moisture profiles and further drying of the sample. A previous work has shown that repeated interruptions of the drying experiment have no significant effect on drying kinetics [14]. A classical back projection algorithm is used to reconstruct 2D scans. Measurement of external area and crack extent has been performed by image analysis as detailed elsewhere [15].

Rheometer

As sludges are viscoelastic materials presenting simultaneously viscous and elastic properties [16], oscillation tests have been chosen to characterise their rheological properties, namely the elastic and viscous moduli. In this kind of test, samples are submitted to a sinusoidal stress or strain depending of the device. Frequency or stress sweep can be performed. In this study a constant stress rheometer (Bohlin Rheometer CS, Bohlin, UK) equipped with a parallel plate system (gap $=2 \mathrm{~mm}$ ) has been used. This parallel plate configuration has been shown to be easier to use (sample preparation and loading) with soft solids, than cone and plate or concentric cylinders [17]. An oscillation frequency sweep between 0.1 and $20 \mathrm{~Hz}$ at a fixed stress of $100 \mathrm{~Pa}$ has been applied to the samples. The level of stress was chosen 
sufficiently low to remain in the linear response zone of the material. The temperature of the base plate was fixed at $20^{\circ} \mathrm{C}$.

\section{RESULTS AND DISCUSSION}

Drying Behaviour

Figure 1 shows the Krisher' s curves (see Materials and Methods section) corresponding to the 5 sludges. The 5 samples present their own drying behaviour and different maximum drying intensities. The drying time ranges from 20 minutes (sludge B) to 45 minutes (sludge E). Sludge B dries clearly faster than the other ones. The analysis is a little bit more tricky for sludges A, C, D and E because some curves partially overlap. It seems however that a trend can be pointed out: the drying rates of theses samples can be classified in the inverse order of their organic content (see volatile contents in Table 2). This ranking is confirmed by the corresponding water evaporation capacities, $\mathrm{C}_{\mathrm{evap}}$, whose determination is interesting for drying design purposes. This parameter represents the amount of water removed by unit of sample area and unit of time. For the 5 samples, the water evaporation capacities $\left(\mathrm{kg} \mathrm{m}^{-2} \mathrm{~s}^{-1}\right)$ corresponding to the removal of $90 \%$ of initial water have been calculated according Equation (i). $M, M_{s}$, $\mathrm{A}_{0}$ and $\mathrm{t}$ represent the initial (wet) mass and final (dry) sample mass, initial sample area and the drying time, respectively. Values are given in Table 3 in an increasing order of volatile solid contents.

$$
\mathrm{C}_{\text {evap }}=\frac{0.9\left(\mathrm{M}-\mathrm{M}_{\mathrm{s}}\right)}{\mathrm{A}_{0} \mathrm{t}}
$$

The influence of the volatile solid content could be explained by internal transfer limitations. Interactions between water and organic matter could indeed hinder water mobility inside the sludge. Similar trends of the evaporation capacity versus the organic content have also been observed in other types of drying equipment such as indirect driers (see e.g., [18]).

This interpretation does not take into consideration dewatering parameters which can have an influence on the final structure. However, we have shown in a previous work [13] that, for sludges B and 
$\mathrm{D}$, neither the dewatering pressure drop, nor the polyelectrolyte dose have a significant impact on the drying behaviour. The same observations are reported by others [7].

\section{Rheological Properties}

Figures 2 and 3 show the evolutions of elastic and viscous moduli versus the applied oscillation frequency. The five sludges behave in similar ways. Their moduli slightly increase with frequency and their elastic contributions are markedly larger than the viscous ones. This indicates all these sludge samples behave mainly like solids. If we except sludge B, both elastic and viscous moduli can be classified following an increasing order of cake siccity. This is illustrated in Figure 4 which presents the evolution of elastic moduli measured at $3.75 \mathrm{~Hz}$ versus the sludge siccity. Sludge samples A, C, D and E are fitted by a same power law. Sludge B seems to be out of this fit. This difference with sludges A,C, D and $\mathrm{E}$ is confirmed by considering the elastic moduli of lab-scale dewatered samples of sludge $\mathrm{B}$ (see Materials and Methods) whose siccities ranges from 12.9 to $15.4 \%$. These data are not significantly different from the elastic modulus of the one-site dewatered sample B and can be fitted by the same power law.

The two power law fittings presented in Figure 4 illustrate clearly that water content is one of the essential parameters affecting the rheology of sludges. This also confirms rheological properties should be compared at identical water contents (or siccities) in order to infer consistent information on their drying behaviour. Under such conditions, the harder the material (i.e. the higher the elastic modulus), the faster the drying rate.

However, the rheological properties of a sludge is not sufficient by themselves to explain all differences in drying behaviour. Sludges A, C, D and E behave approximately in the same way from a rheological viewpoint whereas their drying behaviours are different and seem to be dependent on the organic content. Other factors such as wastewater origin and treatment conditions can affect in a complex way the sludge composition (fat content, fibre content, type of microorganisms, exopolymers). 
Final Texture

X-ray microtomography allows obtaining cross-sections images of the samples at different stages of drying, giving an illustration of the textural changes occurring within the samples. Figure 5 shows cross-sections of the five sludge samples after complete drying. It can be seen that these samples can be grouped in two categories of sludges as already observed for their rheological properties. Sludges A, C, $\mathrm{D}$ and $\mathrm{E}$ present very similar characteristics: an external crust delimiting a big void, even though sludge A has a slightly more 'spongy' texture. Sludge B is more compact, with some cracks mostly radially oriented. These images also allow comparing shrinkage: sludge B undergoes the most important volume reduction. The crust formation observed with samples A, C, D and E is possibly related to internal transfer limitations. Indeed, if the internal water transport is not fast enough to feed the external surface exposed to hot air, a superficial desiccation occurs, which hardens the external border of the final product. Further drying causes internal shrinkage, creating internal voids. This role played by internal transfer limitations agrees with differences in drying fluxes observed when comparing the Krisher' s curves of the different samples (Figure 1).

\section{CONCLUSIONS}

This paper brings a contribution to a necessary research effort in the field of drying of WWTP sludges. Sludge drying remains a particularly complex operation whose performance, e.g., the evaporation capacity strongly depends on sludge origin and properties. The organic content and the rheological behaviour of the sludges are key parameters. The five investigated sludge samples can be grouped into two distinct sludge families. Sludges A, C, D and E present similar rheological properties mainly depending on their water content. The drying kinetics of these four sludges decreases with increasing organic content and, finally, they undergo the same kind of textural modifications, with formation of an external crust. Sludge B clearly present a different rheological behaviour. Its elastic and viscous moduli are higher, at similar siccities, than those of sludges A, C, D and E. Moreover, this sludge 
dries faster and keeps a more compact structure by undergoing a larger shrinkage, which could be related to low internal transfer limitations. The role of rheological properties and/or organic content on the level of internal transfer limitations is not yet well understood and should be completed by other studies. An interesting perspective would be to classify sludges on the basis of their composition, rheological properties and WTTP process characteristics in order to determine relations with their drying behaviours. This would require a large-scale survey to confront data acquired by different researchers involved in sludge drying, sludge dewatering and wastewater treatment

\section{ACKNOWLEDGEMENTS}

A. Léonard is grateful to the FNRS (National Fund for Scientific Research - Belgium) for a Scientific Research Worker position.

\section{REFERENCES}

1. Conseil de l' Union Européenne. Directive 1991/271/EC du 21 mai 1991 du Conseil relative au traitement des eaux urbaines résiduaires. OJ L 135 30.05.1991. (1991).

2. OTV, Traiter et valoriser les boues. Infinités Communication, Rennemoulin, (1997).

3. Conseil de l' Union Européenne. Directive 1999/31/EC du 26 avril 1999 du Conseil relative à la mise en décharge des déchets. OJ L 182 16.07.1999. (1999).

4. Apesa, Eléments bibliographiques. Apesa (Association Pôle Environnement Sud Aquitain), (2000).

5. ADEME and Cabinet Arthur Andersen, Examen de la situation de la filière de recyclage agricole des boues d'épuration urbaines en Europe et dans divers autres pays du monde. ADEME Editions, (1999).

6. Numrich R. and Brown B.W., Sludge drying with mechanical vapour re-compression. UTA International, 2, 126-130 (1997). 
7. Vaxelaire J., Bongiovanni J.-M. and Puiggali J.R., Mechanical dewatering and thermal drying of residual sludge. Environ. Technol., 20, 29-36 (1999).

8. Chen G., Yue P.L. and Mujumdar A.S., Sludge dewatering and drying. Dry. Technol., 20, 883-916 (2002).

9. Ferrasse J.-H., Arlabosse P. and Lecomte D., Heat, momentum, and mass transfer measurements in indirect agitated sludge dryer. Dry. Technol., 20, $749-769$ (2002).

10. Léonard A., Blacher S., Marchot P. and Crine M., Use of X-ray microtomography to follow the convective heat drying of wastewater sludges. Dry. Technol., 20, 1053-1069 (2002).

11. Nadeau J.-P. and Puiggali J.R., Séchage. Des processus physiques aux procédés industriels. Technique et Documentation - Lavoisier, Paris, (1995).

12. ASAE. ASAE Standard. American Society of Agricultural Engineers (ed.). D245.5, 452-464. 1996. St. Joseph, Michigan.

13. Léonard A. Etude du séchage convectif de boues de station d' épuration Suivi de la texture par microtomographie à rayons X. PhD Thesis, Université de Liège, Belgique (2003).

14. Léonard A., Blacher S., Marchot P. and Crine M., X-ray microtomography : a new tool to follow soft material shrinkage during convective drying. In: Proc. of the $2^{\text {nd }}$ World Congress on Industrial Process Tomography, Aug. 2001, Hanover, Germany, pp. 110-117 (2001).

15. Léonard A., Blacher S., Marchot P., Pirard J.P. and Crine M., Image analysis of X-ray microtomograms of soft materials during convective drying. J. Microsc., 212 , 197-204 (2003).

16. Baudez J.C. Rhéologie et physico-chimie des boues résiduaires pâteuses pour l' étde du stockage et de l' épandage. PhD Thesis, Ecole Nationale du Génie Rural, des Eaux et Forêts, Paris (2001).

17. Macosko C.W., Shear rheometry: drag flows. In: Rheology. Principles, measurements, and applications, Macosko C.W. (ed.), Wiley/VCH, Poughkeepsie, NY, pp. 181-236 (1994).

18. Chavez-Nunez S. Séchage par contact avec agitation de boues résiduaires urbaines : influence de leur origine et des conditions opératoires sur la cinétique de séchage et les caractéristiques des boues sèches et des rejets gazeux. PhD Thesis, Université de Perpignan, France (2004). 
Table 1. Characteristics of the 5 WWTPs chosen to collect dewatered sludges

\begin{tabular}{|c|c|c|c|c|}
\hline WWTP & $\mathrm{EH}$ & Effluent & Tertiary Treatment & Other \\
\hline A & 8000 & Domestic & None & Thickening + Belt filter \\
\hline B & 9000 & Domestic & None & Thickening + Belt filter \\
\hline $\mathrm{C}$ & 18000 & Industrial (agrofood) & None & $\begin{array}{l}\text { Sludge digestion }+ \\
\text { Thickening }+ \text { Belt filter }\end{array}$ \\
\hline $\mathrm{D}$ & 27000 & Domestic & $\begin{array}{l}\text { Nitrification- } \\
\text { Denitrification } \\
\text { (intermittent stage) }\end{array}$ & Thickening + Belt filter \\
\hline $\mathrm{E}$ & 110000 & $\begin{array}{l}\text { Domestic }(50 \%)+ \\
\text { industrial (agrofood) }\end{array}$ & $\begin{array}{l}\text { Nitrification- } \\
\text { Denitrification } \\
\text { Dephosphotation } \\
\text { (precipitation) }\end{array}$ & $\begin{array}{l}\text { Thickening + } \\
\text { Centrifugation }\end{array}$ \\
\hline
\end{tabular}

Table 2. Dry solids and volatile solids contents of the 5 sludges after mechanical dewatering; Dry solids contents of sludge B dewatered at the laboratory

Collected after mechanical dewatering Collected after thickening -

Dewatered at the laboratory

\begin{tabular}{llll}
\hline Sludge & DS (\%) & VS (\% DS) & DS (\%) \\
\hline A & 14.9 & 58.7 & from 12.9 to 15.4 \\
B & 14.3 & 57.4 & \\
C & 12.7 & 66.4 & \\
D & 16.9 & 68.9 & \\
E & 21.4 & 74.7 & \\
\hline
\end{tabular}


Table 3. Water evaporation capacities corresponding to the removal of $90 \%$ of initial water content

$\begin{array}{lllll}\text { B } & \text { A } & \text { C } & \text { D } & \text { E }\end{array}$

\begin{tabular}{|c|c|c|c|c|c|}
\hline Water evaporation capacity $\left(\mathrm{kg} \mathrm{m}^{-2} \mathrm{~s}^{-1}\right)$ & $1.9610^{-3}$ & $1.4610^{-3}$ & $1.4110^{-3}$ & $1.3410^{-3}$ & $0.9610^{-3}$ \\
\hline Volatile solids (\% DS) & 57.4 & 58.7 & 66.4 & 68.9 & 74.7 \\
\hline
\end{tabular}


Figure 1. Krischer' s curves (drying flux versus normalisedwater content) for extrudates of the 5 sludges - Temperature $=160^{\circ} \mathrm{C}$; Superficial velocity $=3 \mathrm{~m} \mathrm{~s}^{-1}$; Ambient humidity.

Figure 2. Elastic modulus versus oscillation frequency for samples of the 5 sludges.

Figure 3. Viscous modulus versus oscillation frequency for samples of the 5 sludges.

Figure 4. Elastic modulus (at a frequency of $3.75 \mathrm{~Hz}$ ) versus siccity for samples of the 5 sludges (collected after dehydration) on the one hand and for samples of sludge B (collected after thickening) dewatered up to different levels at the laboratory on the other hand. Two solid lines represent the power law fitting on sludges A, C, D and E, and on sludge B dewatered at the laboratory.

Figure 5. Cross-sections obtained by X-ray microtomography of completely dried samples of the 5 sludges. 